\title{
PREVALÊNCIA DA AUTOMEDICAÇÃO ENTRE ESTUDANTES DA UNIVERSIDADE FEDERAL DO SUL DA BAHIA - UFSB - CAMPUS SOSÍGENES COSTA
}

\author{
PREVALENCE OF SELF-MEDICATION AMONG STUDENTS AT THE FEDERAL \\ UNIVERSITY OF SOUTH BAHIA - UFSB - CAMPUS SOSÍGENES COSTA
}

\author{
Cryskelle Martins Xavier ${ }^{1}$, Raquel Siqueira da Silva²
}

1 - Farmacêutica, acadêmica do Bacharelado interdisciplinar em Saúde na Universidade Federal do Sul da Bahia - Campus Sosígenes Costa, Porto Seguro - Ba.

2 - Doutora em Psicologia, professora adjunta da Universidade Federal do Sul da Bahia.

\section{RESUMO:}

A automedicação é uma prática de autocuidado comum na sociedade, todavia pode causar sérios danos a saúde do indivíduo. Nesse contexto, foi realizado um estudo de delineamento transversal com objetivo de estimar a prevalência da automedicação entre os estudantes da Universidade Federal do Sul da Bahia, campus Sosígenes Costa na cidade de Porto Seguro - BA, buscando conhecer as principais justificativas de uso dos medicamentos e influências para sua prática. Participaram da pesquisa 100 estudantes que responderam a um questionário online, semiestruturado, contendo questões sociodemográficas e relacionadas à automedicação. Os dados foram tabulados utilizando-se o programa Microsoft office Word 2007®. Em relação à automedicação, $87 \%$ dos participantes admitiram uso de medicamentos sem prescrição nos últimos três meses. Os itens mais utilizados na forma de automedicação foram os analgésicos e antitérmicos $(49,7 \%)$. A justificativa para a prática de uso mais citada foi dor de cabeça (33,5\%). A maior parte $(38 \%)$ declarou ter realizado o uso por conta própria, ademais, $75 \%$ dos estudantes afirmaram conhecer as implicações negativas da automedicação e apenas $11 \%$ deles assumiram tem sofrido reações adversas decorrentes do uso de medicamentos sem prescrição. Como evidenciado na pesquisa com os estudantes da Universidade Federal do Sul da Bahia - Campus Sosígenes Costa são preocupantes os índices da auto-administração de remédios sem prescrição, inclusive entre pessoas com maior grau de instrução, por isto é importante realizar a conscientização dos acadêmicos.

Palavras - chave: Automedicação. Estudantes. Uso de medicamentos.

\section{ABSTRACT:}

Self-medication is a human behavior self-care practice in society, but it can cause serious harm to one's health. In this context, a cross - sectional study was carried out to estimate the prevalence of self - medication among students of the Federal University of Southern Bahia, Sosígenes Costa campus in the city of Porto Seguro - BA, seeking to know the main justifications for the use of medicines and influences for their practice. The study included100 students who answered an online, semi-structured questionnaire containing sociodemographic and self-medication questions. Data were tabulated using the Word 2007 program. Regarding self-medication, $87 \%$ of participants admitted to using nonprescription drugs in the last three months. The most used items in the form of self-medication were analgesics and antipyretics (49.7\%). The justification for the most commonly used practice was headache (33.5\%). Most (38\%) reported self-use, more than $75 \%$ of students reported knowing the negative implications of self-medication, and only $11 \%$ of them assumed they have suffered adverse react Self-medication is a human behavior self-care practice in society, but it can cause serious harm to one's health. In this context, a cross - sectional study was carried out to estimate the prevalence of self - medication among students of the Federal University of Southern Bahia, Sosígenes Costa campus in the city of Porto Seguro - BA, seeking to know the main 
justifications for the use of medicines and influences for their practice. The study included 100 students who answered an online, semi-structured questionnaire containing sociodemographic and self-medication questions. Data were tabulated using the Word 2007 program. Regarding selfmedication, $87 \%$ of participants admitted to using nonprescription drugs in the last three months. The most used items in the form of self-medication were analgesics and antipyretics (49.7\%). The justification for the most commonly used practice was headache $(33.5 \%)$. Most $(38 \%)$ reported selfuse, more than $75 \%$ of students reported knowing the negative implications of self-medication, and only $11 \%$ of them assumed they have suffered adverse reactions from non-prescription medications. How evidenced in the search with the students of the UFSB the self-medication administration without prescription are worrisome, including among the people with most of degree education, because of it is important do the awareness of academics ions from non-prescription medications. How evidenced in the search with the students of the UFSB the self-medication administration without prescription are worrisome, including among the people with most of degree education, because of it is important do the awareness of academics.

Keywords: Self-medication. Students. Use of medications.

\section{INTRODUÇÃO}

A automedicação é considerada uma prática de autocuidado no qual o indivíduo utiliza medicamentos sem prescrição médica com intuito de aliviar sintomas e tratar doenças. Segundo Schmid, Bernal e Silva (2010, p. 1041) "a automedicação foi definida pelo uso de pelo menos um medicamento que não tenha sido indicado por médico ou dentista, isto é, indicado por farmacêutico, balconista de farmácia ou outros." De acordo com Schuelter- trevisol et al. (2011, p. 414) "esta prática apresenta alta incidência, tanto em países desenvolvidos quanto em países subdesenvolvidos, atingindo níveis de 68\% e 92\%, respectivamente."

A uso indiscriminado de medicamentos é um incidente danoso à saúde individual e coletiva, uma vez que nenhuma droga é inofensiva. O uso desacertado de substâncias conhecidas, como os medicamentos de venda livre têm potencial de provocar profusas consequências (MUSIAL, DUTRA E BECKER, 2007). Galato, Madalena e Pereira (2012, p. 3326) afirmam que "quando não ocorre a adoção desta prática seguindo os critérios de uso racional de medicamentos, tanto o paciente quanto a sociedade podem ter prejuízos." Corroborando isto o Sistema Nacional de Informações Tóxico-Farmacológicas (Sinitox) indica que ocorreram no Brasil 15846 casos de intoxicações por medicamentos em 2016, sendo destes, 1573 entre pessoas de faixa etária de 20 a 29 anos. (BRASIL, 2016).

Silva et al. (2012, p. 6) afirma que "em relação aos estudantes universitários, especialmente os da área da saúde, os estudos sinalizam para a alarmante frequência de automedicação." O uso de medicamentos sem prescrição é uma ocorrência rotineira entre os universitários e o seu uso desregrado é nocivo à saúde individual e coletiva. "Pesquisas sobre o perfil da automedicação constituem ferramentas importantes para a estruturação 
correta da práxis acadêmica." (SILVA et al. 2012, p. 6).

O uso inadequado de substâncias de fácil acesso pela população, como os analgésicos, xaropes e antiinflamatórios podem acarretar diversas consequências como: reações alérgicas, dependência e sonolência, além disto, o alívio momentâneo dos sintomas pode encobrir a origem da doença, ocasionando assim, agravo para casos clínicos complexos.

Segundo Schuelter-trevisol et al. (2011, p. 415) "no Brasil, existe carência de dados úteis para a promoção de medidas eficazes no combate a automedicação e promoção do uso racional de medicamentos, aspectos esses desenvolvidos e preconizados pela Organização Mundial de Saúde (OMS)."

Neste sentido, considerando a magnitude epidemiológica e os diferentes aspectos envolvidos na ocorrência da automedicação, esse presente estudo indaga qual a prevalência e fatores associados à prática da automedicação entre os estudantes da Universidade Federal do Sul da Bahia-campus Sosígenes Costa. Assim sendo, o objetivo desse estudo foi estimar a prevalência da automedicação entre os acadêmicos da Universidade Federal do Sul da Bahia - UFSB, campus Sosígenes Costa, Porto SeguroBA; identificar as principais justificativas para uso de medicamentos sem prescrição entre os estudantes; analisar as principais influências para a ingestão de medicamentos sem orientação médica e quantificar o conhecimento sobre os riscos da automedicação.

A partir desse estudo com dados reais acerca dos fatos acima citados, será possível propor programas educativos e oficinas de estudo que abranjam essa temática, visto que é importante discutir essa questão objetivando conscientizar os acadêmicos a respeito da automedicação e seus riscos para saúde, colaborando para otimização das políticas públicas em saúde da comunidade.

\section{METODOLOGIA}

Foi realizado um estudo de delineamento transversal, com caráter quantitativo discreto, composto por uma amostra de 100 estudantes da Universidade Federal do Sul da Bahia - campus Sosígenes Costa, Porto Seguro-BA. Para coleta de dados utilizou-se um formulário online semi-estruturado com variáveis sociodemográficas (sexo, etnia, com quem vive, renda familiar, curso e período), perfil de consumo de medicamentos com período recordatório nos últimos três meses que antecederam a coleta dos dados, como também, o conhecimento a cerca das implicações negativas dessa prática. 
A aplicação do questionário decorreu entre os meses de abril e maio de 2018. Os estudantes foram convidados a participar da pesquisa por meio de grupos em redes sociais relacionados com a instituição. A UFSB tem campi nos municípios de Itabuna, Teixeira de Freitas e Porto Seguro, sendo assim, a variável dependente consistiu em concordar com o termo de consentimento livre esclarecido (TCLE) e ser estudante da Universidade Federal do Sul da Bahia no campus Sosígenes Costa em Porto Seguro .

Os medicamentos foram identificados pelo nome genérico e classificados conforme o sistema de classificação "Anatomical Therapeutic Chemical" (ATC), preconizado para os estudos sobre medicamentos pela OMS. Os sintomas citados pelos estudantes foram convertidos para a Classificação Internacional de Doenças e Problemas Relacionados à Saúde (CID).

Os dados foram tabulados e analisados repetidas vezes, através de tabelas e gráficos criados no programa Microsoft office Excelß e Microsoft office Word® para Windows e demonstram as informações obtidas na amostra.

\section{RESULTADOS E DISCUSSÃO}

A amostra, como apresentada na TABELA 1, traz as características em relação ao sexo, etnia, com quem vive e renda familiar dos entrevistados. Quanto ao perfil, os resultados mostraram que o maior número de participantes foi do sexo feminino (60\%), acompanhando o perfil nacional, pois segundo Souza et al. (2011, p. 5) "no Brasil, estudos apontaram as mulheres como mais representativas em relação à prática de automedicação." Como também a classificação étnica, à maioria se declararam negros e pardos, $81 \%$ da amostra.

Mais de $50 \%$ dos participantes declararam morar com familiares ou parceiros e a renda familiar predominante foi de 1-2 salários mínimos (35\%). Podemos perceber que mesmo a pesquisa sendo realizada dentro de um grupo relativamente pequeno quando comparado a população nacional os perfis sócios demográficos dominantes se mostram com características proporcionais. 
Tabela1: Perfil sociodemográfico da amostra.

\begin{tabular}{|c|c|c|}
\hline \multirow{2}{*}{$\begin{array}{l}\text { Características Sociodemográficas } \\
\text { Sexo }\end{array}$} & \multicolumn{2}{|c|}{ acadêmicos } \\
\hline & $\mathbf{N}^{\circ}$ & $\%$ \\
\hline Masculino & 39 & 39 \\
\hline Feminino & 60 & 60 \\
\hline Não binárie & 1 & 1 \\
\hline \multicolumn{3}{|l|}{ Etnia } \\
\hline Negro & 34 & 34 \\
\hline Pardo & 47 & 47 \\
\hline Indígena & 2 & 2 \\
\hline Branco & 17 & 17 \\
\hline \multicolumn{3}{|l|}{ Com quem vive } \\
\hline Familiar ou parceiro & 58 & 58 \\
\hline República & 18 & 18 \\
\hline Sozinho & 24 & 24 \\
\hline \multicolumn{3}{|l|}{ Renda familiar $\left(\mathrm{SM}^{\star}\right)$} \\
\hline Não possui & 21 & 21 \\
\hline Até $1 \mathrm{SM}$ & 24 & 24 \\
\hline 1 a 2 SM & 35 & 35 \\
\hline 3 a 5 SM & 11 & 11 \\
\hline Mais de $5 \mathrm{SM}$ & 9 & 9 \\
\hline
\end{tabular}

Fonte: Dados referentes aos questionários respondidos pelos acadêmicos da Universidade Federal do Sul da Bahia - Campus Sosígenes Costa, Porto Seguro, 2018.

*SM=salário mínimo $=954,00$ reais.

Como pode ser observado no GRÁFICO 1 a amostra teve uma partilha de participação acadêmica balanceada, contemplando alunos de todos os bacharelados interdisciplinares e como esperada, com uma maior disposição em responder ao formulário 
pelos estudantes do bacharelado interdisciplinar em saúde (35\%), visto que a temática é relacionada ao curso.

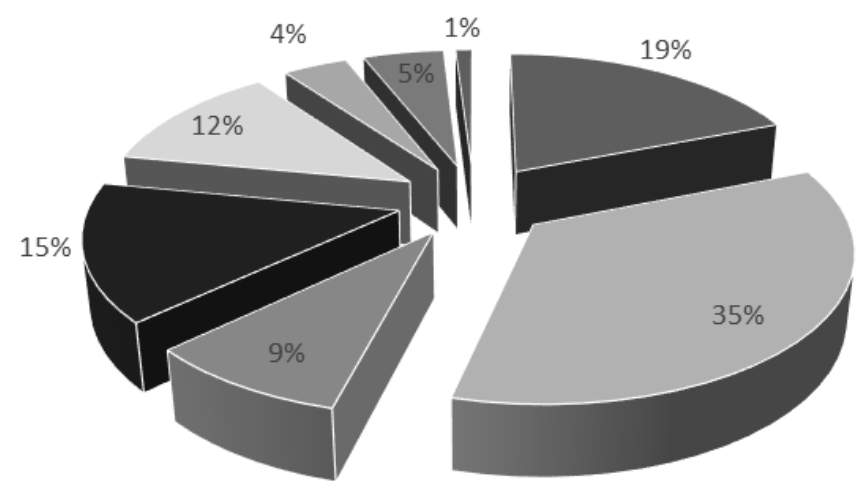

GRÁFICO 1 - ÁREA DE FORMAÇÃO

- ABI " BI-Saúde " BI-Humanidades - BI-Ciências "Bl-Artes " LIs Direito - Pós

Fonte: Dados referentes aos questionários respondidos pelos acadêmicos da Universidade Federal do Sul da Bahia - Campus Sosígenes Costa, Porto Seguro, 2018.

Como a universidade tem um processo de ingresso anual com entrada no segundo quadrimestre do ano, à pesquisa teve maior índice participativo de alunos que cursam o $3^{\circ}$, $9^{\circ}$ e $6^{\circ}$ quadrimestre, respectivamente, estando no período de coleta dos dados $33 \%$ dos entrevistados cursando o $3^{\circ}$ quadrimestre, $22 \%$ o nono $\left(9^{\circ}\right)$ e $19 \%$ o sexto $\left(6^{\circ}\right)$.

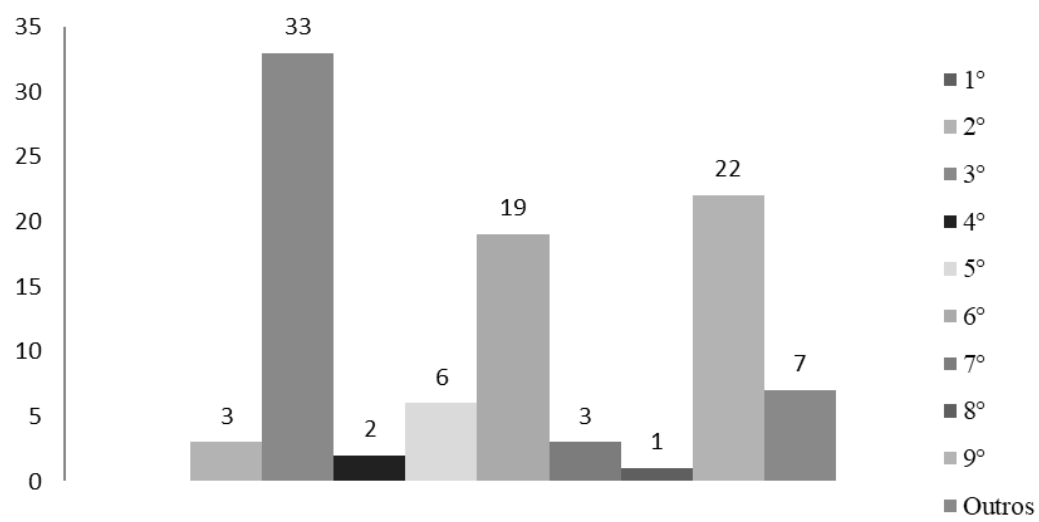

GRÁFICO 2 - QUADRIMESTRE ATUAL

Fonte: Dados referentes aos questionários respondidos pelos acadêmicos da Universidade Federal do Sul da Bahia - Campus Sosígenes Costa, Porto Seguro, 2018. 
Foi encontrada entre os acadêmicos da UFSB - CSC uma prevalência de automedicação nos últimos três meses de $87 \%$, havendo entre os 100 alunos pesquisados apenas 13 (treze) não praticado o uso de medicamento sem prescrição médica ou odontológica no período supracitado. Percebe-se com os dados obtidos que a automedicação é uma forma terapêutica usual entre os estudantes dessa instituição de ensino superior.

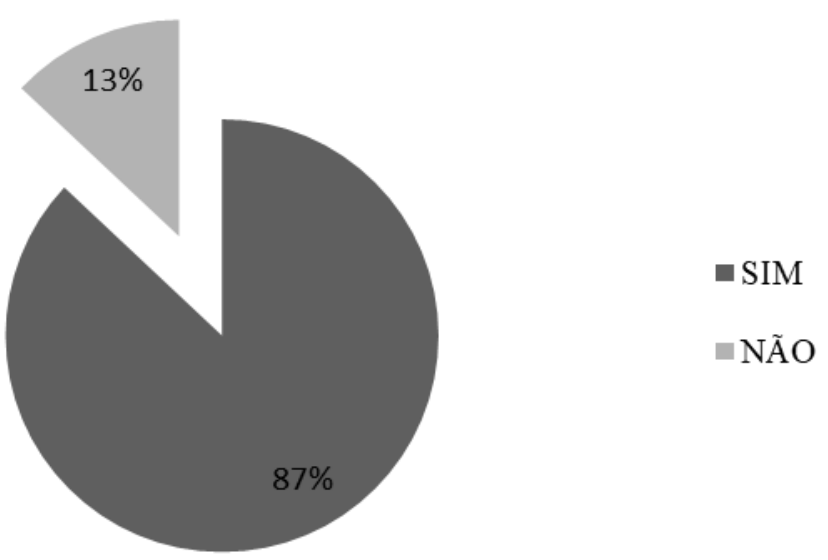

\section{GRÁFICO 3 - AUTOMEDICAÇÃO NOS ÚLTIMOS 3} MESES

Fonte: Dados referentes aos questionários respondidos pelos acadêmicos da Universidade Federal do Sul da Bahia - Campus Sosígenes Costa, Porto Seguro, 2018.

"A automedicação pode ter consequências danosas, independentemente da doença, do sintoma ou do medicamento usado. No caso da dor isso é ainda mais verdadeiro." (MARTINEZ et al. 2013, p. 92). Foi observado na pesquisa que $49 \%$ dos entrevistados fizeram uso de medicamentos sem orientação para aliviar dor ou febre. De acordo com Souza et al. (2011, p.2) "a pessoa que vivencia a experiência dolorosa busca alívio através de aconselhamento médico, terapias complementares de saúde e/ou automedicação." 
Tabela 2: Medicamentos mais utilizados pelos entrevistados nos últimos três (3) meses.

\begin{tabular}{lcc}
\hline & \multicolumn{2}{c}{ Acadêmicos } \\
Medicamento & No & $\%$ \\
\hline Analgésico/antitérmico & 97 & 49,7 \\
AlNE/corticóide de uso sistêmico & 33 & 16,9 \\
Vitamina/Antianêmico & 4 & 2,1 \\
Antibiótico/antimicótico/antiviral/ & 11 & 5,6 \\
antiparasitário de uso sistêmico & & 1,5 \\
Preparações para tosse e & 3 & \\
resfriado/expectorante & & 0,5 \\
Corticóide de uso tópico & 1 & 2,1 \\
Antiasmático/descongestionante & 4 & 2,6 \\
Antidepressivo/ansiolítico/ anticonvulsivante & 5 & 100 \\
Antiespasmódico & 11 & 5,6 \\
Outros** & 26 & 13,4 \\
Total & 195 & \\
\hline Fonte: Dados referentes & & \\
\hline
\end{tabular}

Fonte: Dados referentes aos questionários respondidos pelos acadêmicos da Universidade Federal do Sul da Bahia - Campus Sosígenes Costa, Porto Seguro, 2018.

Nota: Houve mais de uma resposta por participante.

** Agrupou hormônio sexual, outros hormônios, miorrelaxante, anti-histamínico, antiácido/antiúlcera, anorexígeno, betabloqueador, antiglicêmico.

Quanto à influência para a automedicação o maior percentual de alunos afirmou ter usado por conta própria (38\%), seguido da indicação de um familiar (14\%). Dos entrevistados $12 \%$ atribuíram o uso a prescrição antiga e $11 \%$ porque tinha o medicamento em casa, estes fatos podem ser possivelmente justificados por experiências anteriores exitosas com o medicamento. 


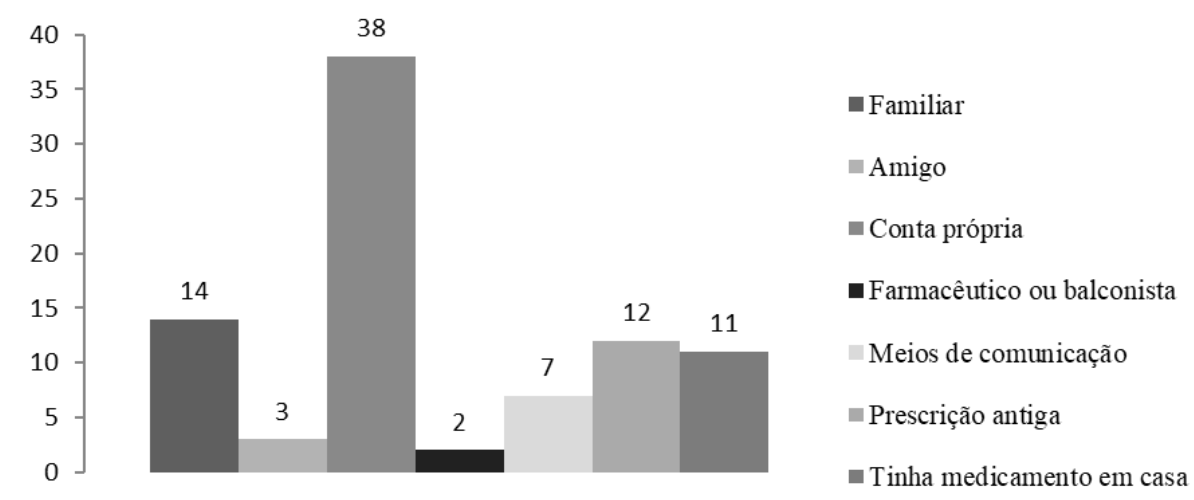

GRÁFICO 4 - INFLUÊNCIA PARA AUTOMEDICAÇÃo

Fonte: Dados referentes aos questionários respondidos pelos acadêmicos da Universidade Federal do Sul da Bahia - Campus Sosígenes Costa, Porto Seguro, 2018.

Ainda a respeito dos dados do GRÁFICO 4, mesmo o Brasil tendo uma legislação que obriga a presença do profissional farmacêutico no estabelecimento apenas $2 \%$ dos entrevistados justificou o uso do medicamento a influência de um profissional farmacêutico ou balconista.

Tabela 3: Motivos para automedicação nos últimos três (3) meses.

\begin{tabular}{lcc}
\hline Sintoma & $\mathbf{N}^{\circ}$ vezes citados & Saúde \\
\hline Dor de cabeça & 43 & $\%$ \\
Dor muscular & 15 & 33,5 \\
Cólica & 17 & 11,8 \\
Febre & 6 & 13,3 \\
Gripe/Resfriado & 11 & 4,7 \\
Outros* & 36 & 8,6 \\
Total & 128 & 28,1 \\
\end{tabular}

Fonte: Dados referentes aos questionários respondidos pelos acadêmicos da Universidade Federal do Sul da Bahia - Campus Sosígenes Costa, Porto Seguro, 2018.

*Agrupou rinite, alergia, sinusite, dor de garganta, enjôo, insônia, refluxo, diarréia, ansiedade, conjuntivite, herpes, gastrite, dor estomacal, depressão, dor de dente. 
Segundo Musial, Dutra e Backer (2007, p. 6) "os sintomas mais comuns que resultam no ato de automedicação são infecção respiratória alta, dor de cabeça e dispepsia/má digestão." A amostra seguiu essa dinâmica visto que dores e problemas com resfriado foram os motivos primordiais citados para justificar a automedicação dos alunos. "O tratamento paliativo da dor pode retardar a elucidação do diagnóstico e tratamento adequado da dor, contribuindo para a cronificação da experiência dolorosa." (Souza ET AL. 2011, p.7). Diante disso torna-se preocupante os altos índices de automedicação encontrados na pesquisa.

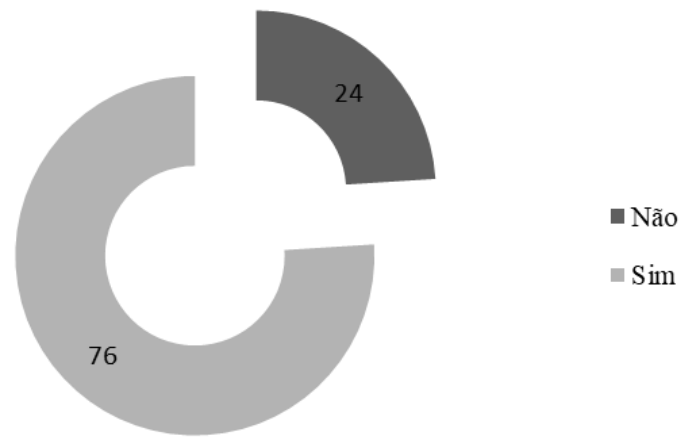

GRÁFICO 5 - CONHECIMENTO ACERCA DAS IMPLICAÇÕES NEGATIVAS DA AUTOMEDICAÇÃO

Fonte: Dados referentes aos questionários respondidos pelos acadêmicos da Universidade Federal do Sul da Bahia - Campus Sosígenes Costa, Porto Seguro, 2018.

Observou-se com o estudo que $76 \%$ dos estudantes conhecem os riscos da automedicação, mas ainda assim a realizam. O elevado percentual de conhecimento das implicações negativas da automedicação nos permite inferir que mesmo com maior índice de conhecimento e acesso facilitado a informação, os universitários não se inibem na hora de realizar esta prática, pelo contrário, como cita Souza e Sena (2017, p. 2) “o conhecimento alcançado sobre os medicamentos proporciona maior confiança para a prática entre os estudantes universitários, em especial, os da área da saúde." 


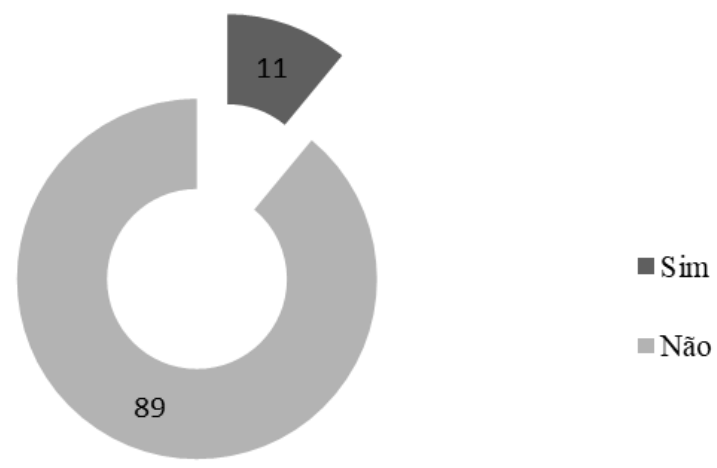

\section{GRÁFICO 6 - REAÇÃO ADVERSA CAUSADA PELO USO DE MEDICAMENTO SEM PRESCRIÇÃO MÉDICA}

Fonte: Dados referentes aos questionários respondidos pelos acadêmicos da Universidade Federal do Sul da Bahia - Campus Sosígenes Costa, Porto Seguro, 2018.

Os estudantes foram interpelados se já sofreram reação adversa causada pelo uso de medicamento sem orientação médica e $11 \%$ afirmaram ter sofrido algum mal estar ao ingerir medicamento sem orientação, portanto $89 \%$ dos entrevistaram negaram qualquer vitimização pelo uso irracional de medicamentos. Dados do Sinitox (2016) mostram que mais de 40\% (15846) dos casos de intoxicação humana por agentes tóxicos no Brasil foram causados por medicamentos, sendo destes apenas 554 citados pela prática da automedicação, ficando a maioria dos casos enquadrados como uso terapêutico e acidente individual, respectivamente.

\section{CONSIDERAÇÕES FINAIS}

Como evidenciado na pesquisa com os estudantes da Universidade Federal do Sul da Bahia - Campus Sosígenes Costa a automedicação é uma prática que merece toda atenção, pois são preocupantes os índices da autoadministração de remédios sem prescrição, inclusive entre pessoas com maior grau de instrução.

Precisam ser incentivados programas de orientação aos estudantes e aos profissionais da área da saúde para diminuição da automedicação entre a população mediante programas de educação em saúde da comunidade e instruções quanto aos riscos e implicações negativas do ato de automedicar-se. 
É importante conscientizar aos acadêmicos, principalmente os da área da saúde a necessidade de assumirem seu papel ante a sociedade, posto que compete a esses futuros profissionais a instrução para a redução dessa prática e por conseguinte, a diminuição dos agravos na saúde das pessoas que se automedicam.

\section{REFERÊNCIAS}

BRASIL. FIOCRUZ. Sistema Nacional de informações tóxico-farmacológicas. 2016. Disponível em: https://sinitox.icict.fiocruz.br/sites/sinitox.icict.fiocruz.br/files//Brasil6_5.pdf>. Acesso em: 09 maio 2018.

DAMASCENO, Dênis Derly et al. Automedicação entre graduandos de enfermagem, farmácia e odontologia da Universidade Federal de Alfenas. Reme - Rev. Min. Enf., Alfenas - Mg, v. 1, n. 11, p.48-52, mar. 2007. Disponível em: <reme.org.br/exportar-pdf/312/v11n1a08.pdf>. Acesso em: 02 maio 2018.

GALATO, Dayani; MADALENA, Jaqueline; PEREIRA, Greicy Borges. Automedicação em estudantes universitários: a influência da área de formação. Ciência \& Saúde Coletiva, Rio de Janeiro, v. 12, n. 17, p.3323-3330, mar. 2012. Disponível em: <http://www.scielo.br/ scielo.php?script=sci_arttext\&pid=S1413-81232012001200017 >. Acesso em: 25 abr. 2018.

GAMA, Abel Santiago Muri; SECOLI, Silvia Regina. Automedicação em estudantes de enfermagem do Estado do Amazonas - Brasil. Rev. Gaúcha Enferm., Porto Alegre, v. 38, n. 1, e65111, 2017. Disponível em: <http://www.scielo.br/scielo.php?script=sci_arttext\&pid =S1983-14472017000100416\&lng=en\&nrm=iso>. Acesso em: 28 abr. 2018.

MARTINEZ, José Eduardo et al. Study of self-medication for musculoskeletal pain among nursing and medicine students at Pontifícia Universidade Católica - São Paulo.Rev. Bras. Reumatol., São Paulo, v. 54, n. 2, p. 90-94, Apr. 2014. Disponível em:< http://www.scielo.br /scielo.php?script=sci_arttext\&pid=S0482-50042014000200090\&Ing=en\&nrm=iso>. Acesso em: 28 abr. 2018.

MUSIAL, Diego. C; SANTOS DUTRA, Josiene; ALEXANDRINO BECKER, Tânia Cristina. A AUTOMEDICAÇÃO ENTRE OS BRASILEIROSalign="justify">. SaBios - Revista de Saúde e Biologia, 
[S.I.], v. 2, n. 2, dez. 2007. ISSN 1980-0002. Disponível em: <http://revista.grupointegrado.br grupointegrado.br/revista/index.php/sabios2/article/view/85/36>. Acesso em: 28 abr. 2018.

MELO, Daniela Oliveira de; RIBEIRO, Eliane; STORPIRTIS, Sílvia. A importância e a história dos estudos de utilização de medicamentos. Revista Brasileira de Ciências Farmacêuticas, São Paulo, v. 42, n. 4, p. 475-485, dec. 2006. ISSN 1809-4562. Disponível em: <http://www.revistas.usp.br/rbcf/article/view/44155/47776>. Acesso em: 28 apr. 2018.

SCHMID, Bianca; BERNAL, Regina; SILVA, Nilza Nunes. Automedicação em adultos de baixa renda no município de São Paulo. Rev. Saúde Pública, São Paulo, v. 44, n. 6, p. 1039 -1045, Dec. 2010. Disponível em: <http://www.scielo.br/scielo.php?script=sci_arttext\&pid= S0034- 89102010000600008\&lng=en\&nrm=iso>. Acesso em: 28 abr. 2018.

SCHUELTER-TREVISOL, Fabiana et al. Automedicação em universitários. Rev Bras Clin Med., São Paulo, v. 6, n. 9, p.414-417, dez. 2011. SILVA, Ruan C. G. et al. Automedicação em acadêmicos do curso de medicina. Medicina (Ribeirao Preto. Online), Ribeirão Preto, v. 45, n. 1, p. 5-11, mar. 2012. ISSN 2176-7262. Disponível em: <https://www.revistas.usp.br /rmrp/article/view/47477>. Acesso em: 28 apr. 2018.

SOUSA, Letícia Abreu de; SENA, Camila Filizzola de Andade. AUTOMEDICAÇÃO ENTRE UNIVERSITÁRIOS DOS CURSOS DE GRADUAÇÃO NA ÁREA DA SAÚDE NA FCV-SETE LAGOAS: INFLUÊNCIA DO CONHECIMENTO ACADÊMICO. Revista Brasileira de Ciências da Vida, [S.I.], v. 5, n. 1, jul. 2017. ISSN 2525-359X. Disponível em: <http://jornal.faculdadeciencias davida.com.br/index.php/RBCV/article/view/115>. Acesso em: 30 abr. 2018.

SOUZA, Layz Alves Ferreira et al. Prevalência e caracterização da prática de automedicação para alívio da dor entre estudantes universitários de enfermagem. Revista Latino-Americana de Enfermagem, Ribeirão Preto, v. 19, n. 2, p. 245-251, apr. 2011. ISSN 1518- 8345. Disponível em: <https://www.revistas.usp.br/rlae/article/view/4312/5528>. Acesso em: 28 apr. 2018.

VILARINO, Jorge F. et al. Perfil da automedicação em município do Sul do Brasil. Rev. Saúde Pública, São Paulo, v. 32, n. 1, p. 43-49, Feb. 1998 . Disponível em: http://www.scielo.br/scielo.php?script=sci_arttext\&pid=S0034-89101998000100006\&lng= 
en\&nrm=iso. Acesso em: 05 maio 2018.

Autor para correspondência:

Cryskelle Martins Xavier

crysanatomy@hotmail.com

Universidade Federal do Sul da Bahia - Campus Sosígenes Costa, Porto Seguro - Ba. Recebido:

18/02/2021 Aceite: 27/03/2021 